\title{
On the Lateral Behavior of the Backfill of a Skew
} \section{Abutment}

\author{
Ali Nojoumi ${ }^{1}$ and Tadeh Zirakian $^{2}$ \\ 1. Department of Mechanical Engineering, Loyola Marymount University, Los Angeles, CA 90045, USA; \\ 2. Department of Civil Engineering and Construction Management, California State University, Northridge, CA 91330, USA
}

\begin{abstract}
It is generally accepted that the interaction between a bridge and its abutment's backfill soil is highly nonlinear, especially under a strong earthquake loading that contains a velocity pulse. For bridges with skew abutments, the superstructure-abutment interaction can dominate the overall bridge performance. This study puts forth a new approach for predicting the lateral capacity of a skew abutment using verified high-fidelity three-dimensional continuum finite element (FE) models. The core idea is that the lateral capacity of a straight abutment is bounded from above and below by that of the abutment of a skew bridge that has the same deck-width, and that of another skew bridge (with the same angle) that has the same backwall length as the original/straight bridge, respectively. This postulation is then used in reverse to estimate the lateral capacity of a skew abutment, given the capacity of a straight but otherwise identical one with an arbitrary length. In prior research, the latter information had already been obtained in closed-form expressions that use physical parameters, such as backfill cohesion, internal friction angle and density, backwall height, and backwall-backfill friction angle. The approach presented here is constrained by the assumption that bridge deck will not rotate during loading. While this assumption is generally violated in a strong earthquake - because a skew bridge will tend to rotate, especially if its in-plane torsional rigidity is low, the model presented does serve as an anchor for parameterizing more advanced (e.g., macro-element plasticity) models that allow rotation, and also as fully parametric lateral response models for torsionally stiff (i.e., multi-span, multi-bent) skew bridges.
\end{abstract}

Key words: Soil-structure interaction, non-rotating abutment walls, numerical simulation.

\section{Introduction}

Abutments are bridge-supporting structures at the interface of the bridge deck and the soil embankment. Fig. 1 (left) displays the components of a seat-type abutment, which is a typical configuration in California, the United States in general, and many parts of the world (see, for example, Refs. [1-3]). During strong seismic events, longitudinal motion of the bridge causes a collision between the deck and the abutment backwall - which is lightly reinforced and is designed to break - and plastic deformations are induced in the backfill. This mechanism is intended to dissipate energy, and concentrate or limit the seismic damage to the abutments [4]. Reversals of inertial forces can

Corresponding author: Ali Nojoumi, clinical assistant professor; research fields: structural and earthquake engineering. E-mail: snojoumi@lmu.edu.

Tadeh Zirakian, assistant professor; research fields: structural and earthquake engineering. E-mail: tadeh.zirakian@csun.edu. cause the deck to unseat from the abutment, and thus, sufficient seat-length is required. Seat-type abutments also feature exterior shear keys that are used to counter possible transverse deck movements. They are proportioned and detailed to act as fuses that will break off under the design earthquake [5].

The abutment-deck interaction becomes even more complex for "skew bridges" (Fig. 1, right). Bridges with skew-angled abutments are constructed to accommodate geometric constraints resulting from the alignment of a waterway or roadway crossing that occurs at an angle that is different from 90 degrees. A significant number of bridges are constructed with some skew [2].

The typical responses of a skew bridge abutment are schematically illustrated in Fig. 3, wherein the abutment reaction is decomposed into its normal and tangential components relative to the backwall. In the absence of skew, significant soil-backwall interaction occurs only in the normal direction, whereas both 
directions contribute in the presence of skew. Moreover, due to the interaction of the bridge superstructure with its abutment, seismic demands on the skew abutment are likely to include lateral translations coupled with torsional rotations in many cases (Fig.2, middle). Currently, there is no validated model for predicting this backfill reaction under the full range of possible abutment motions, and only partial experimental results [6] when the skew bridge is torsionally stiff (Fig.2, right).

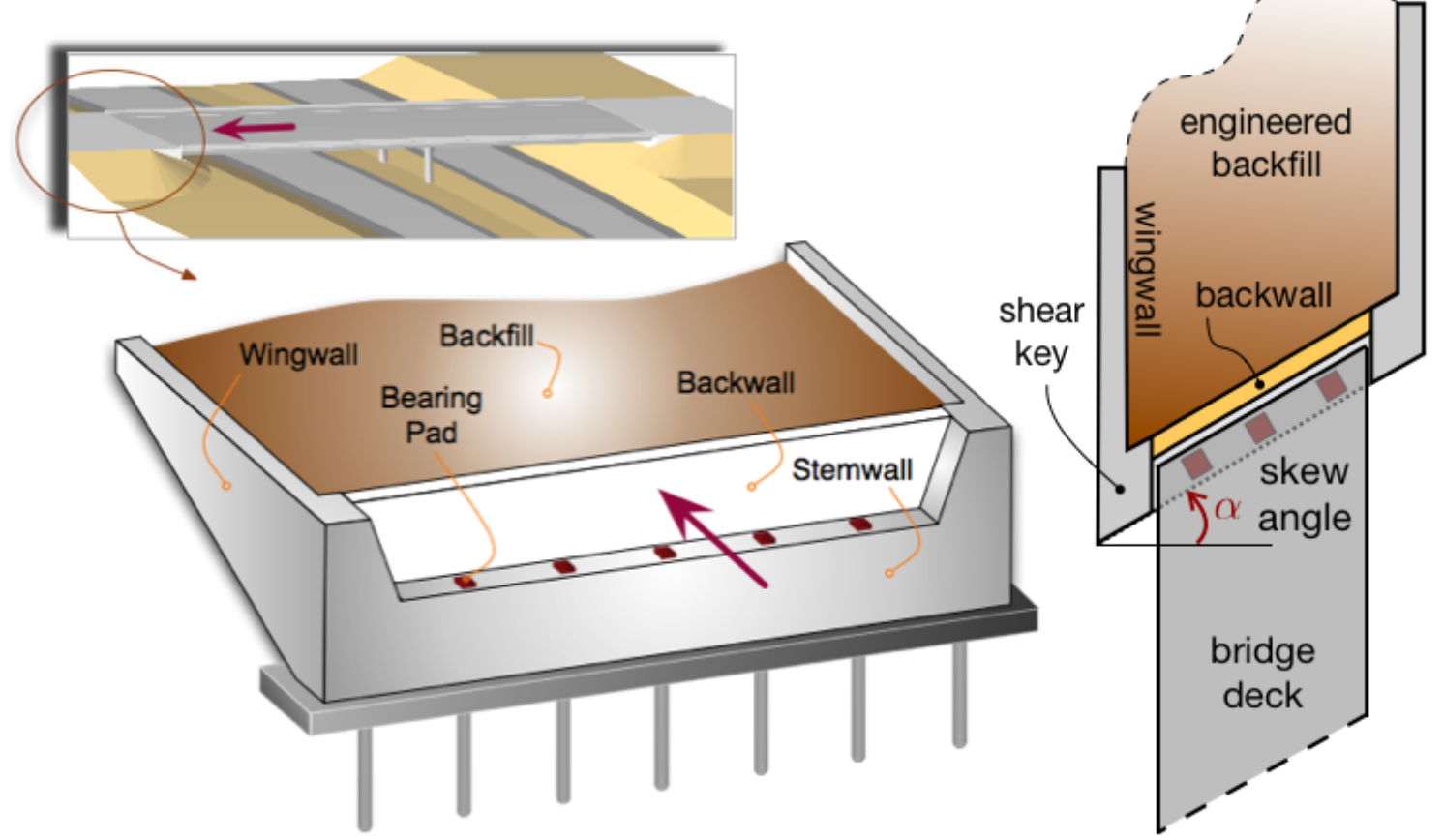

Fig. 1 The anatomy of a seat-type abutment (left), and plan view of a skew configuration (right).
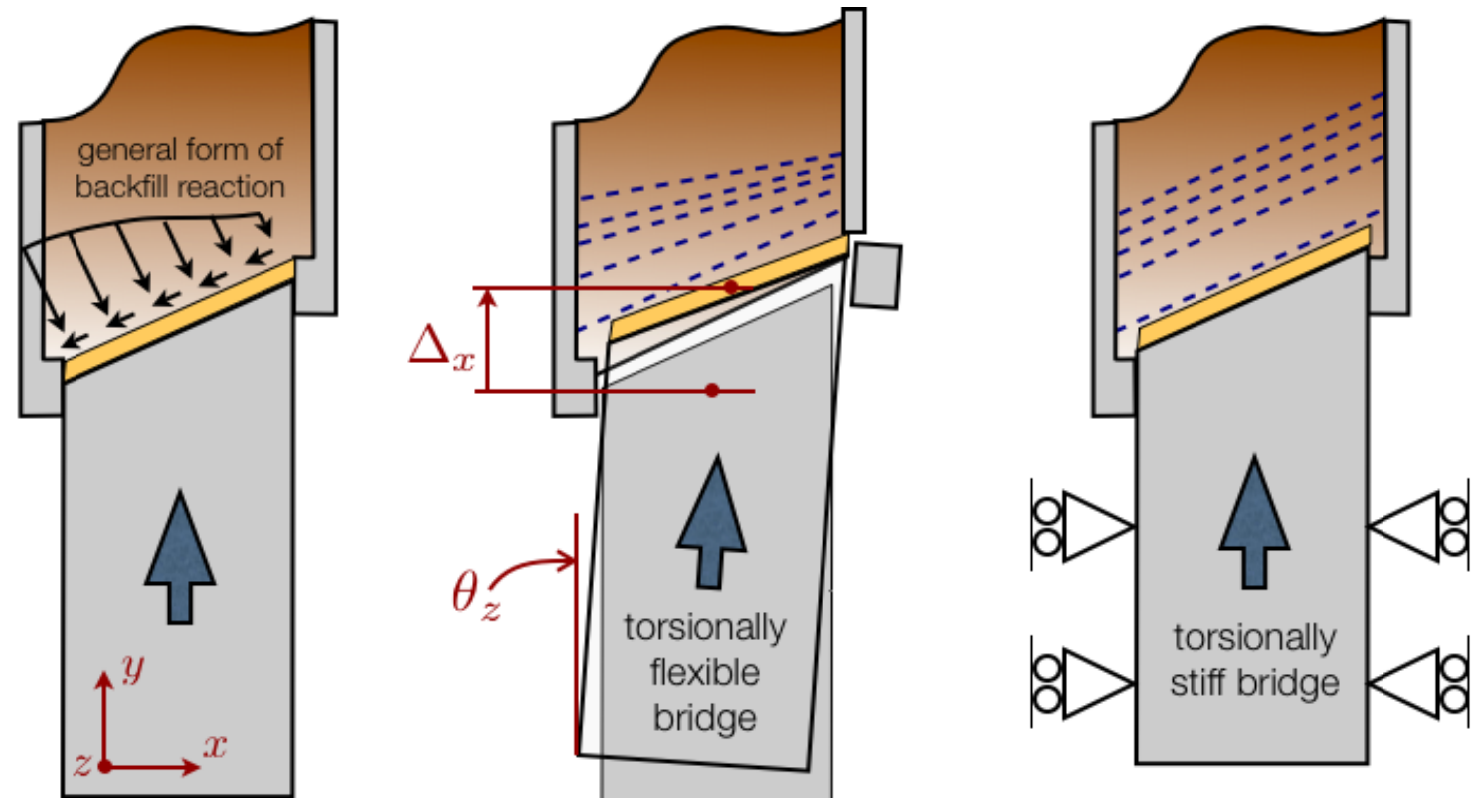

Fig. 2 Tangential and normal components of the backfill reaction (left). Deformation demands from translation and torsional rotations for torsionally flexible (middle) and stiff bridges (right). 
Significant efforts have been undertaken to characterize the nonlinear load-deformation characteristics of non-skew abutments having cohesive and granular backfills $[7,8]$. The current inventory of test data that can be directly applied to develop design guidelines is limited to non-skew backwalls $(\alpha=0)$, backfill materials consisting of well-compacted clay or silty sand of varying relative density, and backfill heights of 1.7 and $2.4 \mathrm{~m}$ (for an overview, for example, Ref. [7]. This inventory only captures abutment-soil response in the normal direction and for zero skew-angle.

This study aims to tackle the relatively restricted case of the lateral — and only lateral — movements of a skew abutment's backwall. The objective is to offer a closed-form expression for lateral behavior that is, by-and-large, based on physical parameters. This expression will be derived in what follows using verified and validated high-fidelity three-dimensional continuum finite element (FE) models. It is expedient to note here that while such a model (i.e., one that only applies to non-rotating backwalls) may appear too restrictive at first, it will be extremely useful in two ways: (1) it will enable the development of a more complex model that is based on resultant-based plasticity, by serving as an anchor point in that model's yield function; and (2) it will directly yield the lateral behavior of a skew abutment that belongs to a bridge that is torsionally stiff in plan (e.g., a bridge with multiple bents) as depicted in Fig. 2 (right).

The remainder of this manuscript is organized as follows: descriptions of the numerical models developed to simulate skew abutments are provided first. Results from these numerical models - namely, FE models developed using Plaxis [9], and a limit equilibrium model, dubbed Log-Spiral Hyperbolic (LSH), by Shamsabadi et al. [7] — are compared to each other, and are validated using data from a full-scale field test. Based on parametric studies using the validated numerical models, a simple relationship is devised using regression techniques, which quantifies the effects of the skew angle on the lateral load-displacement backbone curve (and, incidentally, the lateral capacity). The veracity of the proposed relationship is assessed against 3D FE results through a series of blind predictions, for which the model matrix comprises different combinations of wall widths and skew angles. Because the scenario of a backwall translating only laterally (i.e., no rotations or side-sway) is very unlikely, even for torsionally stiff bridges, a series of sensitivity studies are carried out. These studies provide a quantified understanding of how small rotations and side-sway can affect the backbone curve.

\section{Description of the Finite Element Models and Their Validation}

The software package "Plaxis 3D Foundation" [10] was used for FE simulations of all the non-rotating walls in the present study. Test data by Stewart et al. [8], henceforth referred to as the "University of California, Los Angeles (UCLA) test", were used to validate various aspects of these FE models. All models featured 15-noded quadratic wedge elements to avoid locking. The models prepared for this study typically hadapproximately 50,000 elements (i.e., 360,000 degrees of freedom), which afforded adequate resolutions of the backfill failure mechanism. A representative model is shown in Fig.3, which represents a bridge with a 60-degree skew, and 60ft-wide deck. Other modeling details and the simulation results are presented next.

\subsection{Constitutive Model for the Backfill}

The soil constitutive model for the backfill is arguably the most critical ingredient of the FE simulations. In this study, the "hardening soil" (HS) model available in Plaxis for both two- and three-dimensional FE simulations was chosen, because the HS model was observed to provide results that were more consistent with field test measurements than the 


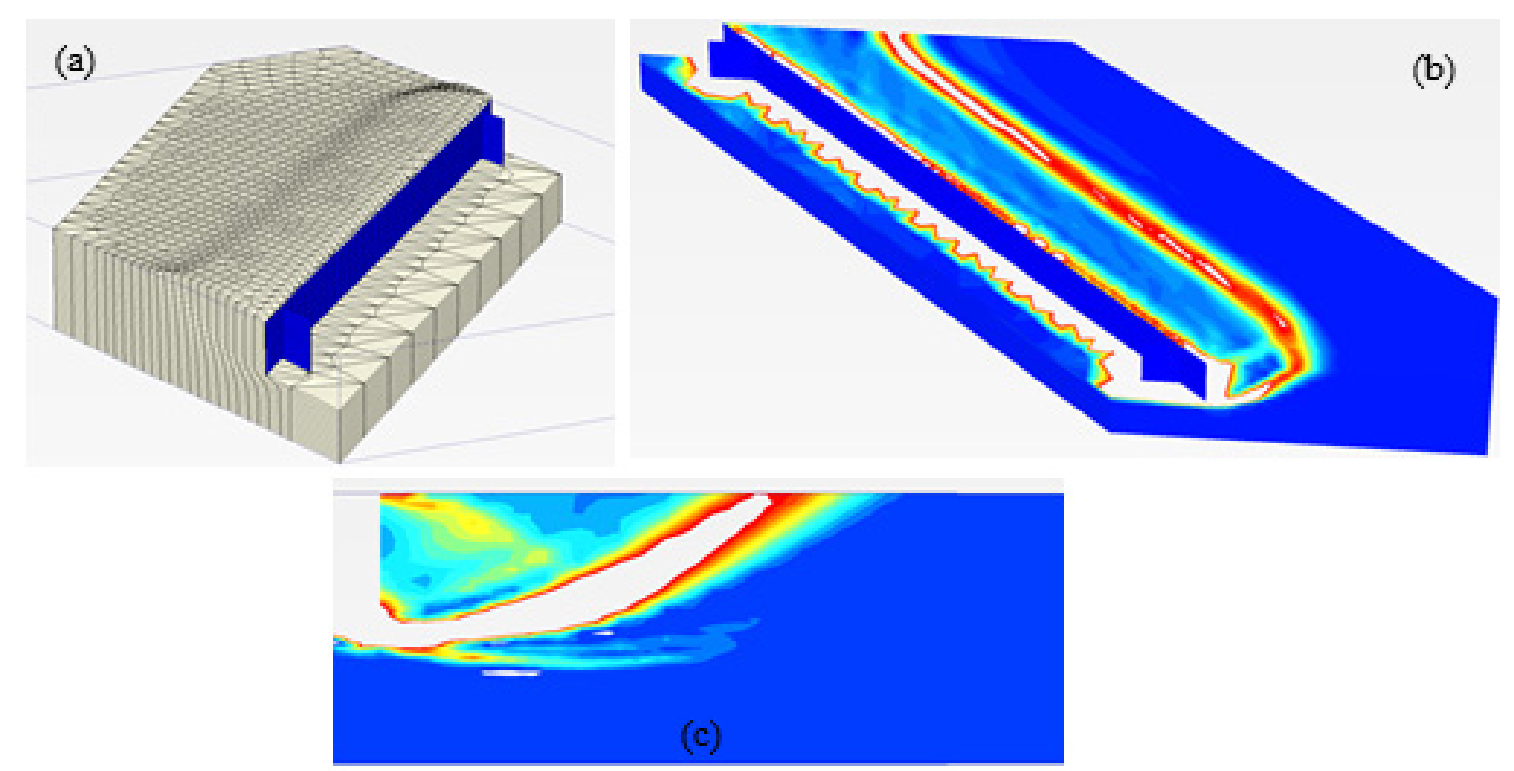

Fig. 3 Typical finite element model used in the present study comprising 53,000 elements: (a) backfill deformations (exaggerated); (b) deviatoric strain distribution plot within the backfill, which indicates the failure surface formation; (c) the side-view of the same.

basic Mohr-Coulomb and Drucker-Prager plasticity models. The HS model is an extension of the well-known hyperbolic model by Duncan and Chang [11] for which the ceiling values for stress are described in similar fashion to the Mohr-Coulomb model, through the friction angle $\varphi$, the soil cohesion $c$, and the dilatancy angle $\psi$. On the other hand, the HS model requires three different input stiffness values - namely, the triaxial stiffness $E_{50}$, the triaxial unloading stiffness $E_{u r}$, and the oedometer loading stiffness $E_{\text {oed }}$. With these parameters, the model takes into account the dependence of stiffness moduli on the stress level (unlike the Mohr-Coulomb model, which neglects this variability), and all three moduli $\left(E_{50}, E_{u r}\right.$, $E_{\text {oed }}$ ) grow with increasing pressure [12].

\subsection{Interface Elements}

In order to model the frictional contact between the abutment backwall and the backfill soil, interface elements with eight-node pairs available in Plaxis3D Foundation v. 2 were used. Each interface element has zero thickness, and is defined by a simple bilinear stress-strain relationship, which describes the response of the backfill-backwall interaction element. This bilinear relationship comprises the classical Coulomb friction model combined with linear elastic loading/unloading rules, and is valid for small displacements and plastic-slip values. The maximum friction angle modeled the structural wall elements and the backfill soil model was 35 degrees. The elements used were zero thickness 8 node, node paring the backfill and the structural elements. For further details on the interface elements used in Plaxis models, one can refer to Shamsabadi et al. [13], and Plaxis 3D Foundation reference manual.

\section{Validation of the FE Model with Data from a Full-Scale Abutment Test}

The material and interface model properties used in the present FE model had been validated by Shamsabadi et al. [13] using data from the UCLA test. The calibrated material properties as well as comparisons with measured lateral load-deflection curves from the said validation effort will be repeated here for the reader's convenience.

As described by Stewart et al. [8], this test involved a $4.6 \mathrm{~m}$-wide, $1.67 \mathrm{~m}$-high seat-type abutment wall pushed against a silty sand backfill compacted up to 
over 95\% modified proctor relative compaction [14]. The wall was configured to mimica seat-type abutment and loading was applied through a cyclic displacement control protocol. The backwall was pushed laterally between two plywood boards that allowed the creation of a plane-strain condition. Inclined actuators, which were providing the necessary lateral forces, were used to suppress any vertical movement. The loading protocol was designed to avoid any separation between the concrete abutment wall and the backfill soil. After the backfill capacity was reached, half of the backfill was excavated in order to visually identify the failure surfaces. The ultimate, (hence the deepest) failure surface extended down from the bottom edge of the abutment wall and reached the backfill ground surface. The horizontal distance from the wall to where the failure surface met the ground surface extended to approximately three times the height of the backwall in a log-spiral shape.

The calibrated (Plaxis) HS model parameters for this test are shown in Table 1. Some of these parameters (cohesion, internal friction angle, density, elastic moduli) were obtained from laboratory (e.g., triaxial) testing, whereas the others were selected initially from literature-suggested values, and were subsequently iteratively adjusted.

The shapes and sizes of backfill failure surfaces, as well as the lateral load-displacement curves were well captured by the FE model (Figs. 4(a) and 5). The lateral total capacity of the abutment backfill was $2,200 \mathrm{kN}$, which is approximately $477 \mathrm{kN} / \mathrm{m}$ (per unit wallwidth). Capacity was reached at a lateral displacement of $5 \mathrm{~cm}$ ( $3 \%$ of abutment height). The residual capacity was $442 \mathrm{kN} / \mathrm{m}$ and was measured at a lateral displacement of $8.5 \mathrm{~cm}$ ( $5 \%$ of abutment height). This brought about the residual capacity of $265 \mathrm{kPa}$ (per unit wall area). Fig. 5 displays the computed lateral load-displacement backbone curve, which mimicked the UCLA test both for capacity and initial stiffness.

\section{Verification of FEM Results with a Semi-analytic Limit Equilibrium Model}

Using the validated FE model, several new FE models were generated. The new models were identical to the original model, except that they had different wallwidths. The objective of this study was twofold: (1) to determine how the backbone curves change/scale with wall-width; and (2) to verify the FE model against a well established (and validated) limit equilibrium model that was devised for straight abutments.

Table 1 Combined list of material parameters for Plaxis "hardening soil"and LS Hmodels for the UCLA test.

\begin{tabular}{|c|c|c|c|c|c|}
\hline \multicolumn{6}{|c|}{ Strength parameters } \\
\hline Unit & $\left(\mathrm{kN} / \mathrm{m}^{3}\right)$ & Friction angle, $\phi(\mathrm{deg})$ & Cohesion, $c(\mathrm{kPa})$ & Wall friction angle (deg) & Dilatancy angle (deg) \\
\hline 20 & & 40 & 14 & 20 & 10 \\
\hline \multicolumn{6}{|c|}{ Other parameters } \\
\hline$R_{\text {int }}$ & Strain, $\varepsilon_{50}$ & Failure ratio, $R_{f}$ & $E_{50}(\mathrm{MPa})$ & $E_{u r}(\mathrm{MPa})$ & Poisson's ratio, $v$ \\
\hline 0.50 & 0.0035 & 0.97 & 70 & 140 & 0.3 \\
\hline
\end{tabular}
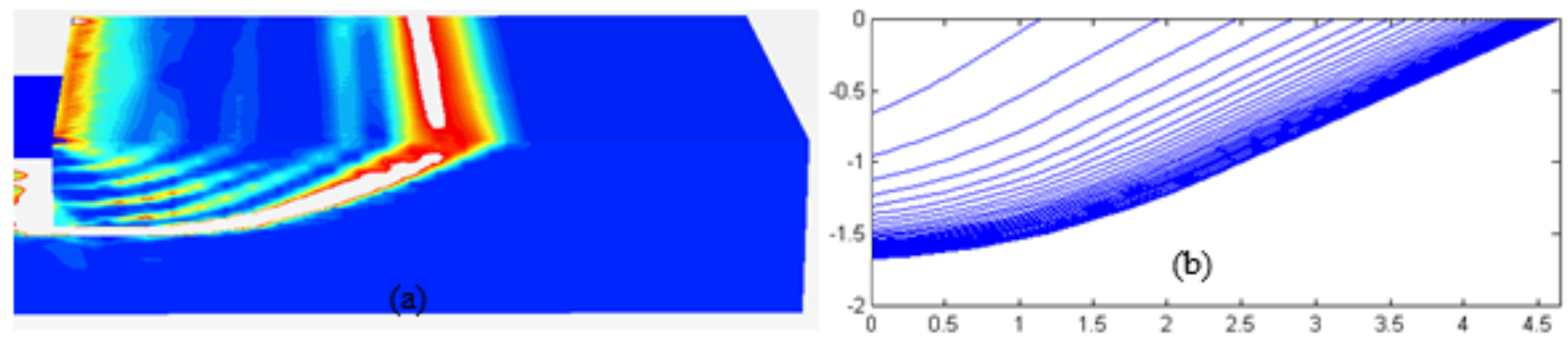

Fig. 4 (a) Incremental deviatoric strain distribution for a straight 15 ft-wide wall obtained using Plaxis; and (b) failure surfaces obtained with the LSH model described in Shamsabadi et al. [7]. 


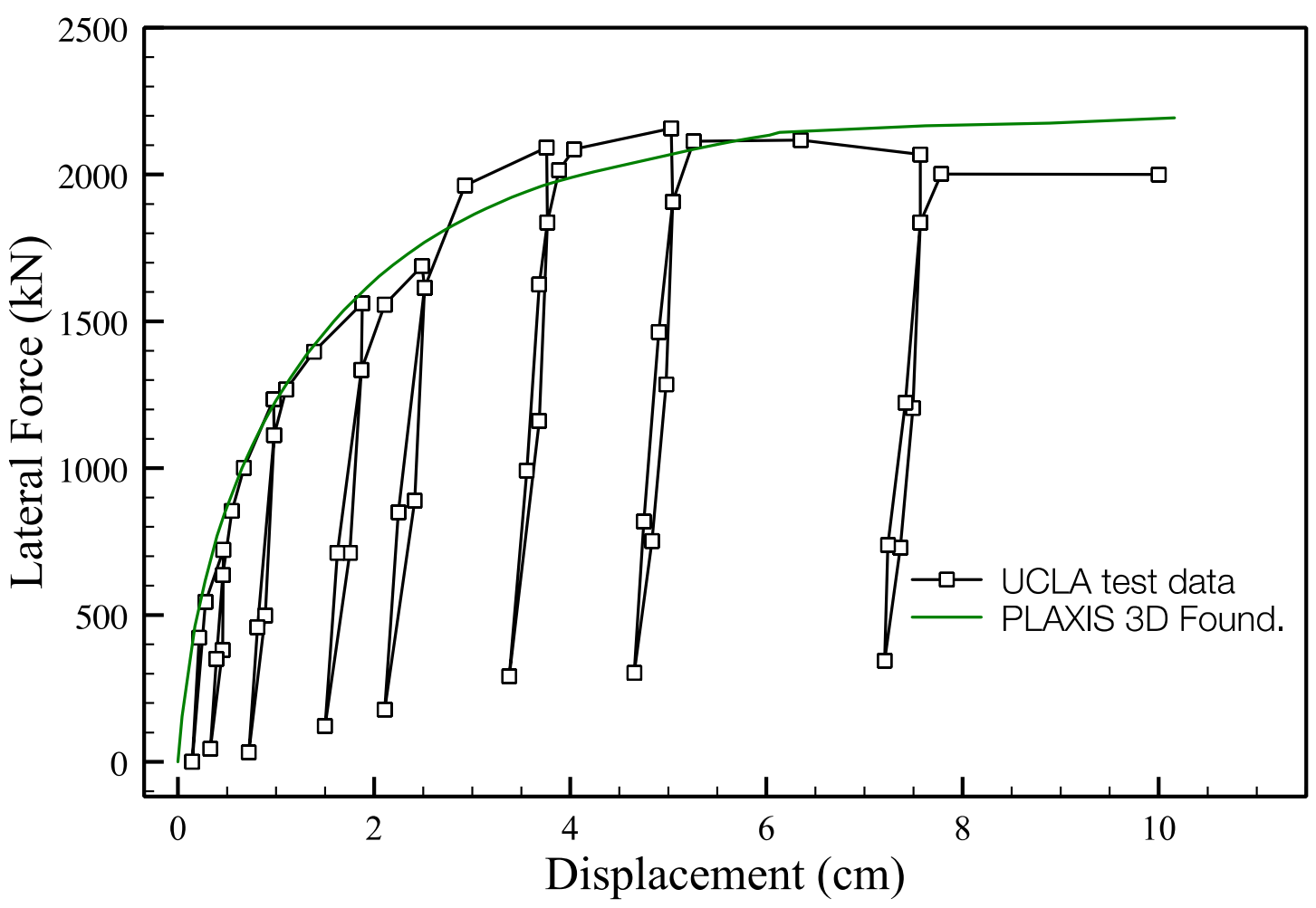

Fig. 5 UCLA full-scale test results (see Stewart et al. [8]) for a $5.5 \mathrm{ft}$-high wall and numerical results from Plaxis 3D foundation.

The aforementioned limit equilibrium model is the log-spiral-hyperbolic (LSH) model described in Shamsabadi et al. [7]. The LSH model is a plane-strain model that utilizes a kinematic hypothesis regarding the shape (a log-spiral curve) of the soil failure surface(s). This model was validated against various field and centrifuge test data (see Shamsabadi et al. [13]). The specific material parameters of the LSH model for the UCLA test are also shown in Table 1. Fig. 4(b) displays the mobilized failure surfaces computed using the LSH model for the UCLA test. These surfaces match very well with both Plaxis results and the measurements taken after the excavation of the backfill at the test site (see Stewart et al. [8]). Deeper failure surfaces correspond to larger lateral wall displacements. As the lateral resistance approaches ultimate capacity in both LSH and Plaxis simulations, new failure surfaces form in the immediate vicinity of the previous ones with diminishing separation towards the ultimate failure surface; therefore the rupture lines are concentrated near the bottom-end of the backwall.

The LSH model calibrated for the UCLA test-which had a backwall width of $4.57 \mathrm{~m}$ (15 $\mathrm{ft}$ ) - was then used in subsequent simulations wherein all model parameters were kept constant, except the wall width, which was varied from $4.57 \mathrm{~m}$ to $36.58 \mathrm{~m}$. Widths less than $4.57 \mathrm{~m}$ were not explored because they are too narrow to encounter in actual bridges. A total of 47 such simulations were carried out in this backwall width range (more-or-less uniformly spaced). The same model matrix was also evaluated using Plaxis.

Fig. 6 displays backbone curves for some of these simulations, wherein it can be seen that the results from LSH and Plaxis are very consistent. Furthermore, the shapes and extents of the failure surfaces predicted in both the LSH and Plaxis simulations are also consistent (as seen in Fig. 4, for example). In both LSH and Plaxis simulations, the ultimate failure surface is observed to intersect the ground line at approximately at $4.7 \mathrm{~m}$ away from the wall. This distance is more-or-less 


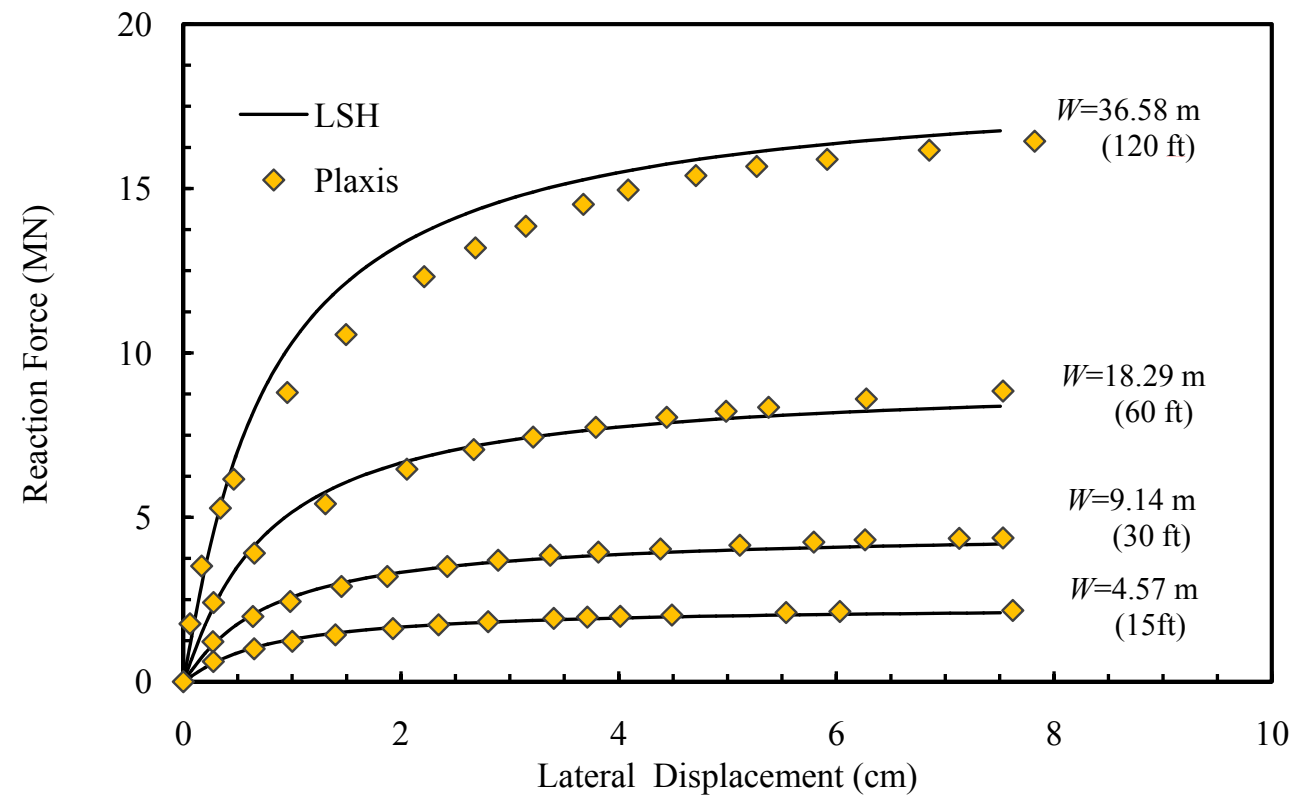

Fig. 6 Lateral load-displacement backbone curves obtained from FE simulations (Plaxis 3D foundation) for straight abutments with different widths, and those obtained using the limit state hyperbolic (LSH) method.

constant for all wall-widths. Since the wall-height was constant in all these simulations, which was $1.67 \mathrm{~m}$ $(5.5 \mathrm{ft})$, it is fair to state the failure surface reaches the ground level at approximately 3 times the wall-height, regardless of the wall-width (at least for the present plane-strain case with UCLA soil).

The results of the aforementioned simulations suggest that Plaxis can be used for geometries and loading conditions other than those that were tested, or simulated using LSH. In particular, with all other parameters being the same, it is fair to state that Plaxis will produce accurate predictions when the wall skew angle is changed from zero to other values. Such parametric studies will be presented next, and those results will be used to develop lateral load-deflection relationships for skew abutments.

\section{Response Correlations between Straight and Skew Abutments}

Using the LSH model — or the Extended Hyperbolic Force Displacement (EHFD) model presented in Shamsabadi et al. [13], which provides the backbone curve in closed-form for different backfill properties and backwall heights - it is possible to obtain the backfill reaction for straight seat-type abutments. The method that will be described below will seek to utilize this information in predicting the response of a skew abutment (for any skew angle) that has the same backfill and backwall height.

The method is based on a simple conjecture: a skew version of a straight abutment will have lower capacity if the skew abutment has the same wall length as the straight one; and a skew version of the straight abutment will have higher capacity if the skew abutment has the same deck-width as the straight one. This is true for any skew angle as long as the backwall is not allowed to rotate about the vertical axis. These lower and upper capacity curves are henceforth referred to as the lower-bound (LB) and the upper-bound (UB) backbone curves, respectively.

The conjecture above means that the two skew configurations will bracket the backbone curve of a straight abutment. That is,

$$
F_{\mathrm{L}}(\Delta) \leq F_{\text {Straight }}(\Delta) \leq F_{\mathrm{U}}(\Delta),
$$

and incidentally (as $\Delta \rightarrow \infty) \quad F_{\mathrm{L}}^{\mathrm{ult}} \leq F_{\text {Straight }}^{\mathrm{ult}} \leq F_{\mathrm{U}}^{\mathrm{ult}}(1)$ where, $F_{L}$ and $F_{U}$ denote the lower and upper-bound lateral passive abutment reactions, and $\Delta$ denotes the 
lateral displacement. This conjecture is tested and demonstrated with three separate Plaxis simulations in Fig. 8 using the UCLA test's backfill properties. The non-skew configuration's wall width was $9.1 \mathrm{~m}(30 \mathrm{ft})$, which corresponds to a typical two-lane bridge. The skew angles for both the upper and lower curves were set at 60 degrees.

The veracity of the conjecture is further examined by carrying out parametric studies with various skew angles. The results (shown in Fig. 8 and Table 2) indicate that the conjecture is valid for skew angles ranging from 15 to 60 degrees and for any abutment width. As expected, Fig. 8 also demonstrates that the UB and LB curves approach the straight abutment curve as the skew angle decreases (obviously, for a 0 -degree skew angle, all three curves are identical). An interesting observation is that the straight abutment curve appears to be almost an average of the UB and LB curves. Nevertheless, since this assertion is not necessarily correct for all skew angles (see the UB and LB capacities for the $60 \mathrm{deg}$ skew walls shown in Fig. $8 \mathrm{~b}$ as well as the values displayed in Table 2). As such, it is necessary to explore the optimal weight(s) for averaging the LB and UB curves.

Before making any further progress, it is important to note that even if an optimal weight can be determined, it is not yet possible to obtain/predict the backbone curve (or capacity) of a skew abutment, given the backbone curve (or capacity) of a straight abutment, which is the objective here. To do so, we must first establish a relationship between the UB and LB backbone curves (and/or capacities). For this purpose, a second conjecture is put forth: the capacities of the UB and LB curves scale linearly. To wit,
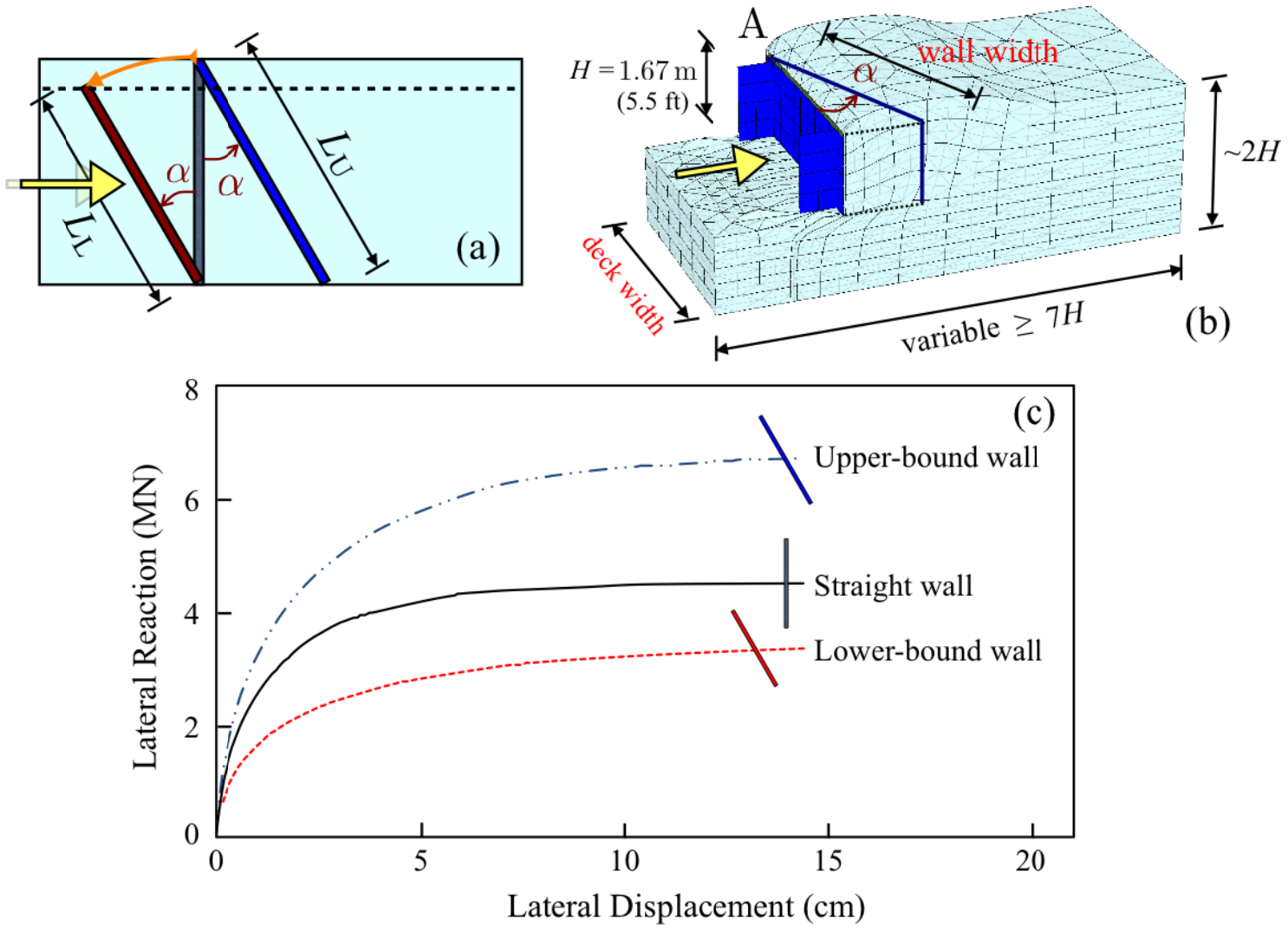

Fig. 7 (a) Schematic plan of the straight abutment and two bounding skewed models for $\alpha$ degrees in the generic configuration of (b) straight/skew abutment FE meshes; (c) backbone curves for a straight abutment (middle curve) with $9.1 \mathrm{~m}$ length, a 60-degree skew abutment with the same deck width (upper curve), and a 60-degree skew abutment with the same backwall width (lower curve) are also shown (all abutments have UCLA backfill). 

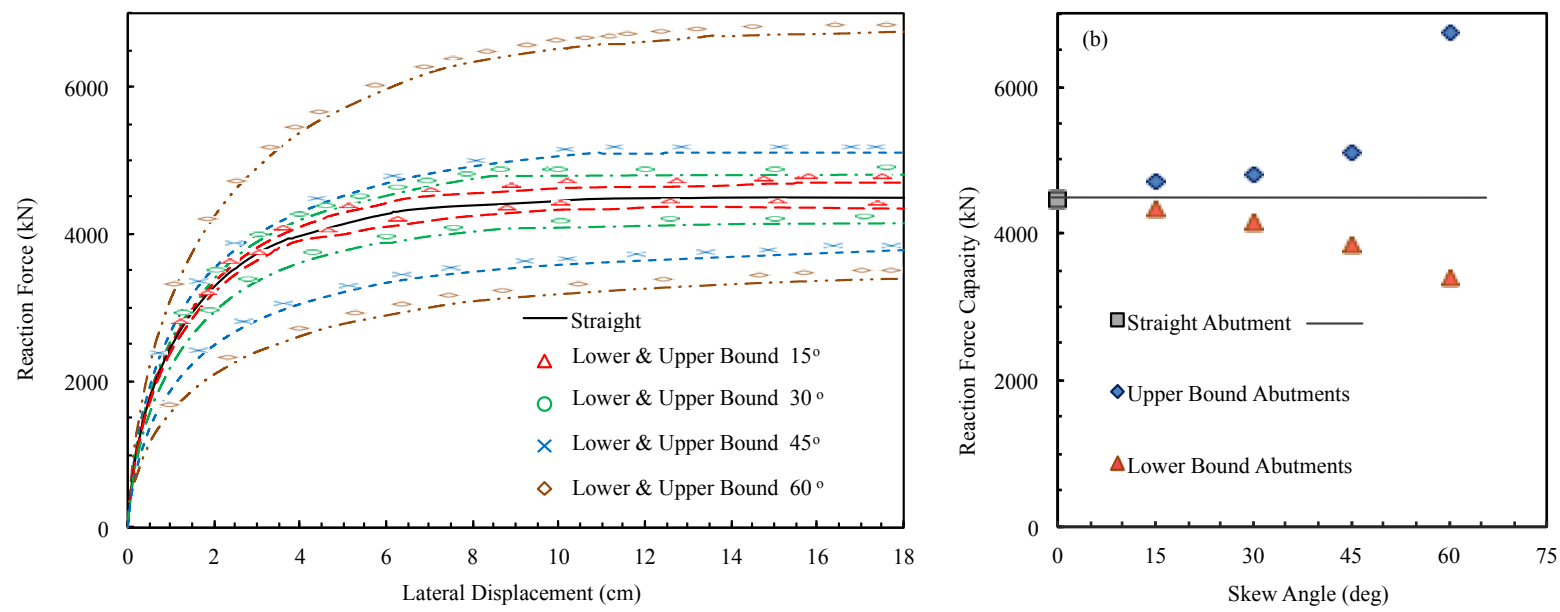

Fig. 8 Response for various skew angles of a $30 \mathrm{ft}$-wide abutment: (a) backbone curves; (b) capacities.

Table 2 Ultimate capacities $(\mathrm{kN})$ vs. different wall widths and skew angles for the study analysis matrix, including the nominal ( 0 degree skew wall) and the upper bound and lower bound limits for each skew angle.

\begin{tabular}{|c|c|c|c|c|c|c|}
\hline$W$ & $0^{\circ}$ & & $15^{\circ}$ & $30^{\circ}$ & $45^{\circ}$ & $60^{\circ}$ \\
\hline \multirow{2}{*}{$\begin{array}{l}4.6 \mathrm{~m} \\
(15 \mathrm{ft})\end{array}$} & \multirow{2}{*}{$2,157.5$} & UB & $2,313.2$ & $2,357.7$ & $2,735.8$ & $3,234.0$ \\
\hline & & LB & $2,081.9$ & $2,032.9$ & $1,783.8$ & $1,592.5$ \\
\hline \multirow{2}{*}{$\begin{array}{l}9.1 \mathrm{~m} \\
(30 \mathrm{ft})\end{array}$} & \multirow{2}{*}{$4,470.6$} & UB & $4,693.1$ & $4,799.8$ & $5,102.3$ & $6,752.7$ \\
\hline & & LB & $4,350.5$ & $4,159.3$ & $3,856.8$ & $3,398.6$ \\
\hline \multirow{2}{*}{$\begin{array}{l}13.7 \mathrm{~m} \\
(45 \mathrm{ft})\end{array}$} & \multirow{2}{*}{$7,001.8$} & UB & $7,357.7$ & $7,468.9$ & $7,891.5$ & $10,556.0$ \\
\hline & & LB & $6,254.4$ & $6,049.8$ & $5,947.5$ & $4,844.3$ \\
\hline \multirow{2}{*}{$\begin{array}{l}18.3 \mathrm{~m} \\
(60 \mathrm{ft})\end{array}$} & \multirow{2}{*}{$9,390.6$} & UB & $10,044.5$ & $10,097.9$ & $11,254.4$ & $1,4074.7$ \\
\hline & & LB & $8,887.9$ & $8,585.4$ & $7,664.6$ & $7,415.5$ \\
\hline \multirow{2}{*}{$\begin{array}{l}22.9 \mathrm{~m} \\
(75 \mathrm{ft})\end{array}$} & \multirow{2}{*}{$12,228.6$} & UB & $12,677.9$ & $13,549.8$ & $14,653.0$ & $16,975.1$ \\
\hline & & LB & $11,886.1$ & $11,748.2$ & $9,243.8$ & $8,105.0$ \\
\hline \multirow{2}{*}{$\begin{array}{l}27.4 \mathrm{~m} \\
(90 \mathrm{ft})\end{array}$} & \multirow{2}{*}{$14,470.6$} & UB & $15,062.3$ & $15,742.9$ & $17,139.7$ & $21,859.4$ \\
\hline & & LB & $14,012.5$ & $13,545.4$ & $11,752.7$ & $11,000.9$ \\
\hline \multirow{2}{*}{$\begin{array}{l}32 \mathrm{~m} \\
(105 \mathrm{ft})\end{array}$} & \multirow{2}{*}{$17,268.7$} & UB & $18,669.9$ & $19,172.6$ & $19,715.3$ & $24,853.2$ \\
\hline & & LB & $17,086.3$ & $15,742.9$ & $14,653.0$ & $14,070.3$ \\
\hline \multirow{2}{*}{$\begin{array}{l}36.6 \mathrm{~m} \\
(120 \mathrm{ft})\end{array}$} & \multirow{2}{*}{$19,105.9$} & UB & $20,649.5$ & $22,375.4$ & $24,377.2$ & $26,814.9$ \\
\hline & & LB & $19,008.0$ & $17,629.0$ & $16,014.2$ & $12,464.4$ \\
\hline
\end{tabular}

$$
\begin{gathered}
\operatorname{CPW}(\alpha) \equiv \frac{F_{\mathrm{U}}^{\mathrm{ult}}}{L_{\mathrm{U}}} \approx \frac{F_{\mathrm{L}}^{\mathrm{ult}}}{L_{\mathrm{L}}}=\frac{F_{\mathrm{L}}^{\mathrm{ult}}}{L_{\mathrm{U}} \cos \alpha} \Rightarrow \\
F_{\mathrm{U}}^{\mathrm{ult}} \cos \alpha \approx F_{\mathrm{L}}^{\mathrm{ult}}
\end{gathered}
$$

where, $\operatorname{CPW}(\alpha)$ denotes capacity per unit wall-length for a given abutment with $\alpha$ degrees of skew. If this conjecture is true, then it will be possible to relate the capacities of UB and LB backbone curves to each other.

This second conjecture can be tested by examining the variation of a dimensionless parameter, dubbed here as MCR (mutual capacity ratio), which is defined as $\mathrm{MCR}_{i j}^{\alpha} \equiv \mathrm{CPW}_{i}^{\alpha} / \mathrm{CPW}_{j}^{\alpha}$. Ideally, if there are no distorting factors (e.g., the boundary effects due to the presence of wingwalls) then $\mathrm{MCR}_{i j}$ will be equal to 1 for any wall length (different values indexed by $i$ 's and $j$ 's here). Fig. 9 displays the MCR values computed for different wall-widths and skew angles, wherein the diagonal elements $\left(\mathrm{MCR}_{i i}\right)$ have unit values, by definition. As seen, the largest violations of the second conjecture are bounded from below and above by approximately $15 \%$. For most of the important cases 

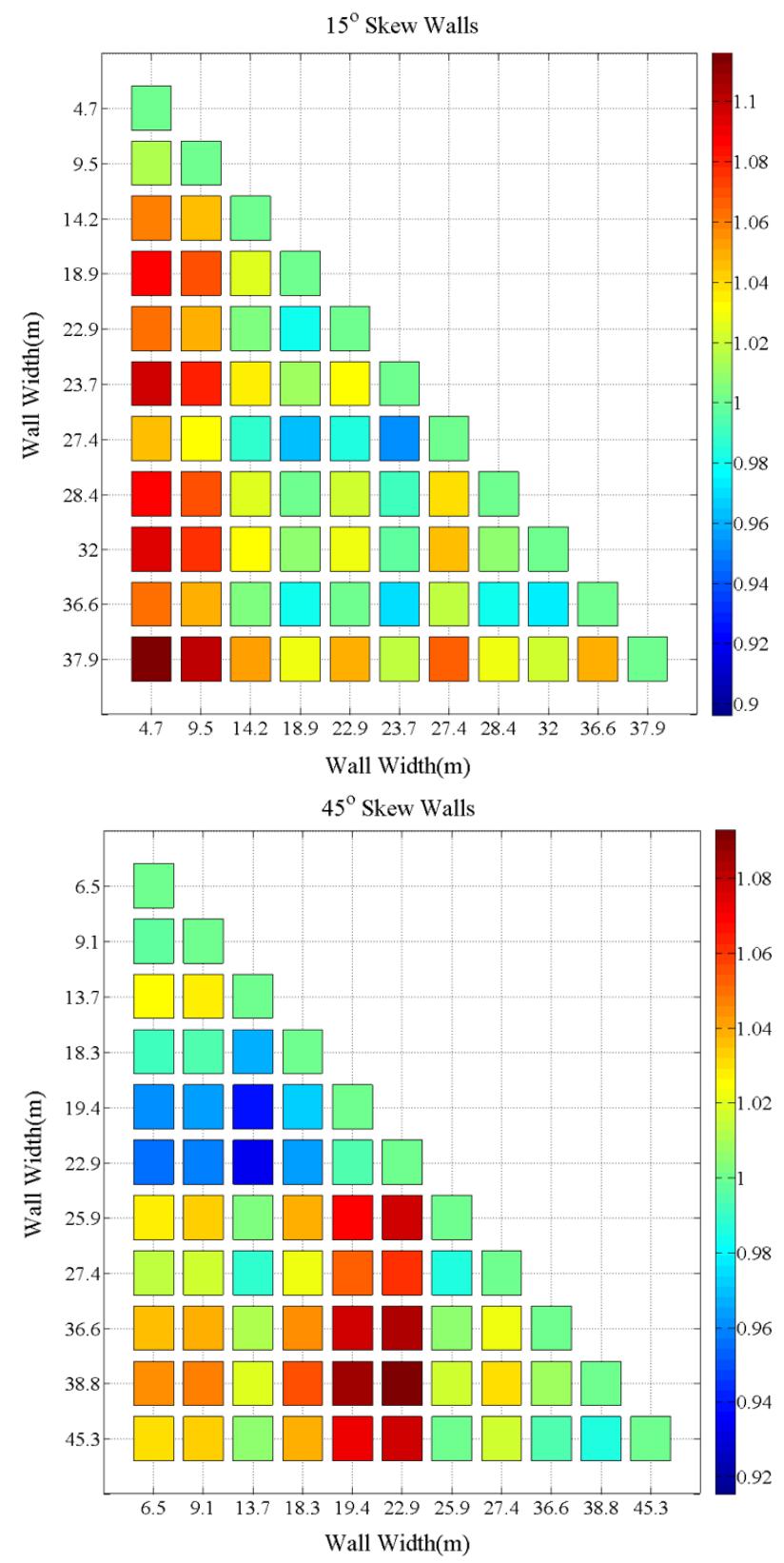

Fig. 9 MCR values for different skew angles.

(i.e., backwall lengths larger than $15 \mathrm{~m}$ and skew angles less than 45 degrees), the second conjecture is even stronger (i.e., $\pm 10 \%$ or less).

\subsection{Correlation Parameter $\lambda$}

With the two conjectures in hand, it is now possible to formulate a direct relationship between (1) the lateral capacities and load-displacement curve of a straight wall and (2) the lateral capacities and
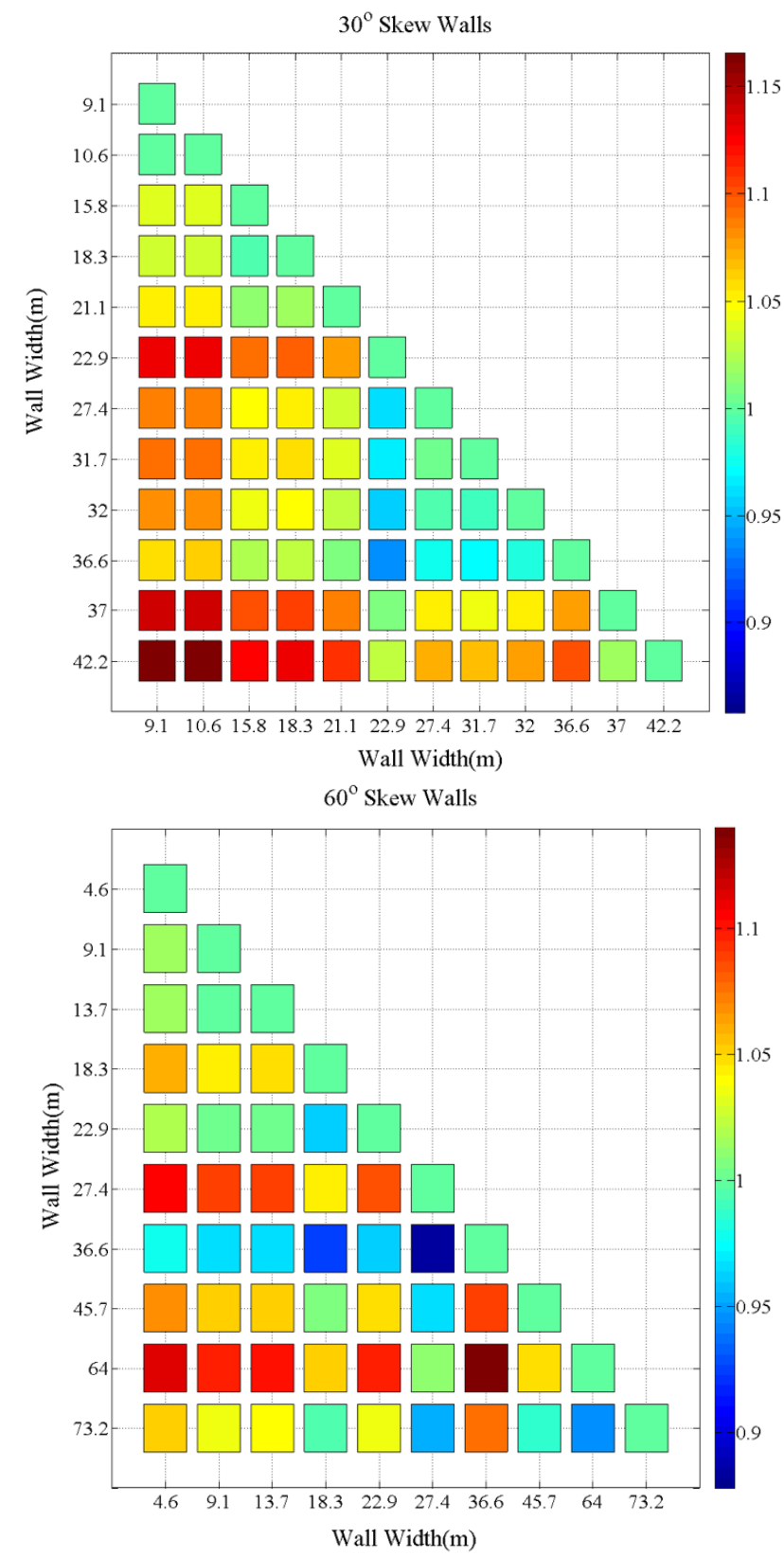

load-displacement curve of a skew-angled version, given any angle $\alpha$, in combination with height and backfill soil properties.

To achieve this, we first introduce the weight (or mixing) $\lambda$ parameter. There will be two different versions of $\lambda$ in this study: one obtained from capacity-only considerations, and another by considering the entire backbone curves. Starting with the capacity-based version, we define $\lambda$ through the 
weighted sum:

$$
F_{\text {Straight }}^{\mathrm{ult}} \approx \lambda F_{\mathrm{L}}^{\mathrm{ult}}+(1-\lambda) F_{\mathrm{U}}^{\mathrm{ult}}
$$

Eq. (3) also implies

$$
\begin{aligned}
F_{\text {Straight }}^{\mathrm{ult}} & \approx \lambda \cos \alpha F_{\mathrm{U}}^{\mathrm{ult}}+(1-\lambda) F_{\mathrm{U}}^{\mathrm{ult}}= \\
& {[1+(\cos \alpha-1) \lambda] F_{\mathrm{U}}^{\mathrm{ult}} } \\
\Rightarrow \quad F_{\mathrm{U}}^{\mathrm{ult}} & \approx[1+(\cos \alpha-1) \lambda]^{-1} F_{\mathrm{Straight}}^{\mathrm{ult}}
\end{aligned}
$$

where, the substitution was made from Eq. (2). Therefore, Eq. (4) represents a relationship between the

capacity of a straight wall and a skew-angled version of it. Given the capacity of a straight abutment, a skew angle $\alpha$, and appropriate value of the mixing parameter $\lambda$, Eq. (4) will yield the capacity of its skew-angled version. It is now only a matter of finding the appropriate values of $\lambda$, which inevitably vary with respect to wall width and skew angle. However, as discussed above in conjunction with the findings presented in Fig. 8 and Table 2, it may be possible to obtain a single optimal value of $\lambda$ that works well for all wall widths and abutment skew angles. This can simply be achieved by defining the minimization problem:

This is a linear least-squares problem and the optimal $\lambda$ value (denoted by $\left.\lambda^{*}\right)$ is:

$$
\left.\frac{\partial e_{\mathrm{ult}}}{\partial \lambda}\right|_{\lambda=\lambda^{*}}=0 \Rightarrow \lambda^{*}=\frac{F_{\text {Straight }}^{\mathrm{ult}}-F_{\mathrm{U}}^{\mathrm{ult}}(\alpha)}{F_{\mathrm{L}}^{\mathrm{ult}}(\alpha)-F_{\mathrm{U}}^{\mathrm{ult}}(\alpha)}
$$

The approach presented above to determine a capacity-based optimal value for $\lambda$ could also be applied equally to the entire backbone curve. In other words, a single/optimal value of $\lambda$ can be obtained, which approximates the entire backbone curve of the skew abutment (not just its capacity value) using that of its corresponding straight abutment. This version of $\lambda$ can be computed by minimizing:

$$
e_{\text {backbone }}(\lambda) \equiv \sum_{i}\left(F_{\text {Straight }}\left(\Delta_{i}\right)-\left[\lambda F_{\mathrm{L}}\left(\alpha, \Delta_{i}\right)+(1-\lambda) F_{\mathrm{U}}\left(\alpha, \Delta_{i}\right)\right]\right)^{2}
$$

where, $\Delta_{i}$ denotes the discrete values of lateral displacement at which the nominal, upperand lower-bound backbone curves are sampled. Again, this is a linear least-squares problem. The optimal $\lambda$ value (denoted by $\lambda^{\#}$ ) is:

$$
\begin{aligned}
& \left.\frac{\partial e_{\text {backbone }}}{\partial \lambda}\right|_{\lambda=\lambda^{\#}}=0 \Rightarrow \\
& \lambda^{\#}=\frac{\sum_{i}\left(\left[F_{\text {Straight }}\left(\Delta_{i}\right)-F_{\mathrm{U}}\left(\alpha, \Delta_{i}\right)\right]\left[F_{\mathrm{L}}\left(\alpha, \Delta_{i}\right)-F_{\mathrm{U}}\left(\alpha, \Delta_{i}\right)\right]\right)}{\sum_{i}\left(F_{\mathrm{L}}\left(\alpha, \Delta_{i}\right)-F_{\mathrm{U}}\left(\alpha, \Delta_{i}\right)\right)^{2}}
\end{aligned}
$$

It is expedient to note here that all three curves in Eq. (8) are generated through 3D FE simulations with force-control and automated sub-incrimination to achieve convergence in equilibrium iterations. As such, they will not necessarily be sampled at identical displacement increments. Therefore, in order to achieve constant displacement increments, we carried out simple searches to the bracket and linearly interpolate the needed capacities between those that were directly obtained from the 3D FE simulation.

Optimal $\lambda$ values given by Eqs. (6) and (8) (i.e., capacity- and backbone-based, respectively) are shown in Fig. 10. As suggested earlier, for both cases, most of the optimal $\lambda$ values are clustered around 0.5. Also, 
according to the definition based on capacities only (Eq. 6), it is always guaranteed that the optimal value is bounded as $0<\lambda^{*}<1$. This is confirmed by results shown in Fig. 10(b). On the other hand, for the backbone-based definition, there are cases in which $\lambda^{\#}$ can reach magnitudes higher than one. This means the straight abutment's backbone curve intercepts the upper-bound backbone curve somewhere before the plateau region. It is useful to note that this only occurred for the wall that had the lowest skew angle and the largest wall length (i.e., the $15^{\circ}$ and $40 \mathrm{~m}$ abutment in Fig. 10(a)).

\subsection{Sensitivity Intervals}

Optimal $\lambda$ values shown in Fig. 10 do not provide the full picture by themselves. It is also necessary to determine how sensitive the least squares fits are to variations in the values of $\lambda$. These sensitivities are computed and presented in the form of $90 \%$ and $95 \%$ sensitivity intervals. A $95 \%$ sensitivity interval indicates that the values of $\lambda$ within this bracket produce a variation of \pm 2.5 at most, in the objective function value. The said intervals are shown in Figs. 11 and 12 for the capacity- and backbone-based $\lambda$ values, respectively.

As seen, for lower skew-angles, the sensitivity intervals are larger, which implies that all three (UB, LB, and straight) response curves are already very close to each other. It can also be deduced from these figures that there is no single $\lambda$ value that falls within
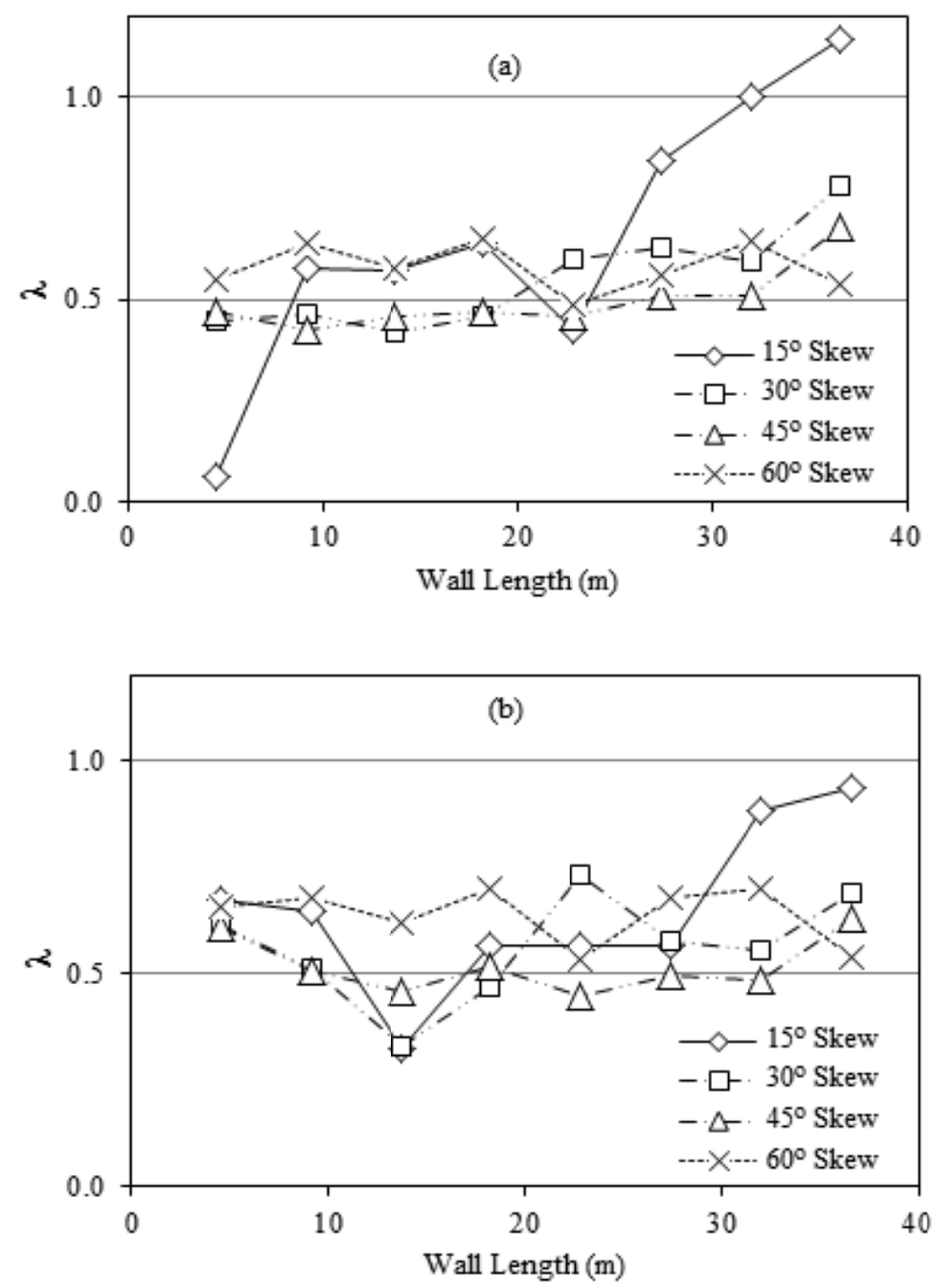

Fig. 10 Optimal $\lambda$ values computed using least-squares minimization on: (a) complete backbone curves; and (b) lateral capacities. 

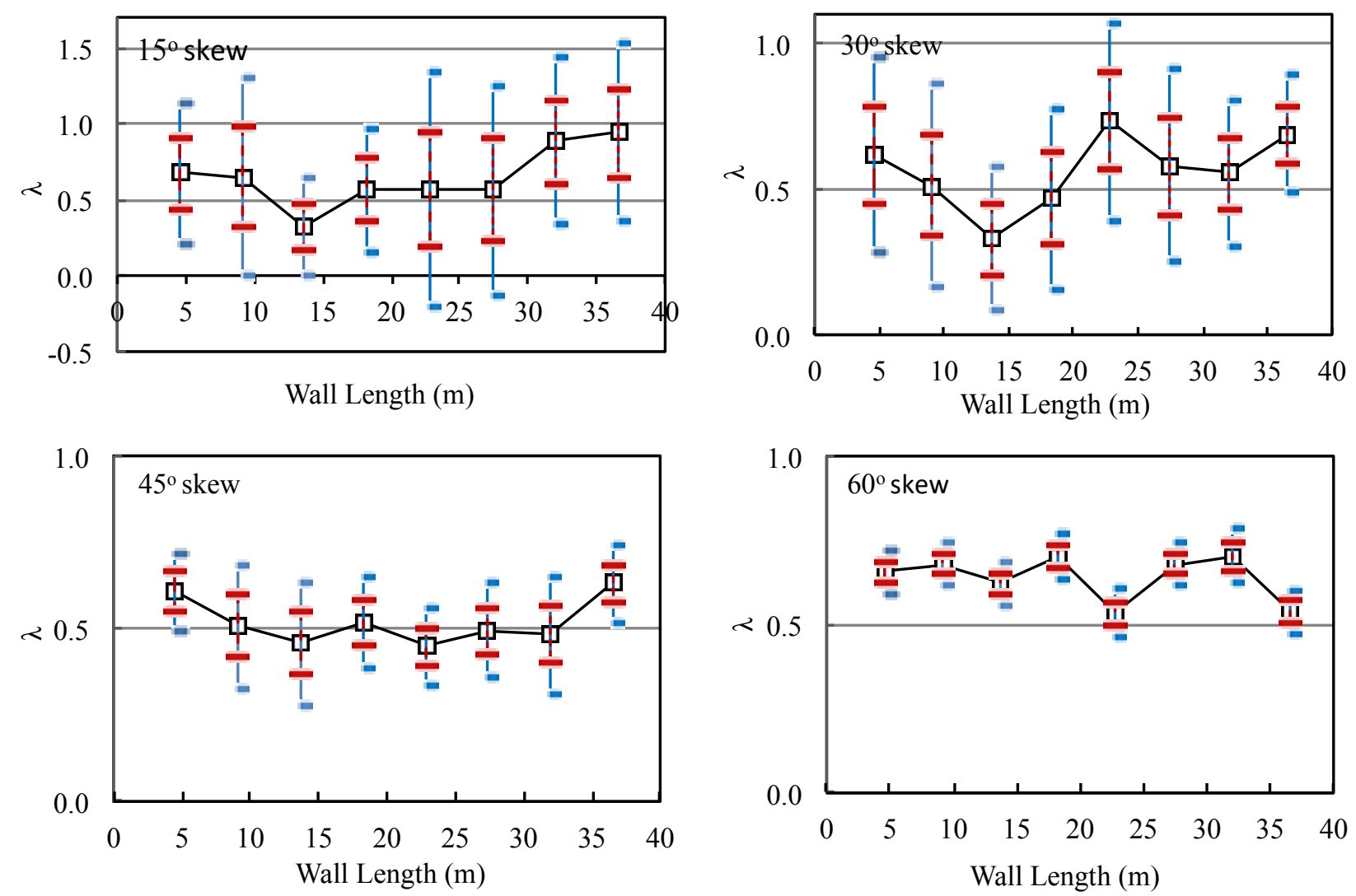

Fig. 11 Capacity-based $\lambda$ values and their $90 \%$ and $95 \%$ sensitivity intervals.

even the looser (i.e., 90\%) sensitivity interval that provides a good fit for all skew angles and wall widths. Nevertheless, it is still possible to produce an acceptable single/constant $\lambda$ value, as described next.

\subsection{A Recommended $\lambda$ Value for Engineering Practice}

Although an optimal $\lambda$ within the $90 \%$ confidence interval was not achieved, it is still possible to introduce a single/constant $\lambda$ value that will provide the minimum possible error when estimating the capacity and backbone curve of a skew-angled bridge (i.e., a pareto-optimal $\lambda$ ). This value can be computed by using the optimal $\lambda$ 's (and their corresponding objective function values) obtained for each skew angle and abutment wall length combination. As stated earlier, this single $\lambda$ value will not be within the $90 \%$ sensitivity interval for all cases, but it can be devised to work very well for most commonly encountered deck widths $(>10 \mathrm{~m}$ or $30 \mathrm{ft})$ and skew angles $\left(<45^{\circ}\right)$.
To compute the pareto-optimal value of $\lambda$, we used three different minimization methods, results of which are shown in Fig. 13. The curve marked as " $L_{1}$ norm" indicates the values of an error function, which was devised by simply adding the absolute values of the differences between the candidate pareto-optimal $\lambda$ (the $x$-axis in Fig. 13) and those optimal $\lambda$ values that are shown in Fig. 11. The alternative approach was to relax the requirements and only to insist on minimizing the $L_{1}$-distance between the pareto-optimal $\lambda$ and those $\lambda$ values that resided within the $90 \%$ sensitivity interval (i.e., the $L_{1}$-distance for a candidate pareto-optimal $\lambda$ is measured from the closest edge of this interval; and if candidate pareto-optimal $\lambda$ is already within the interval, then its $L_{1}$-distance is set to zero). This objective function's value with respect to $\lambda$ is marked as the " $L_{1}+$ dead zone minimization" in Fig. 13. The third and final approach was to introduce a weighting scheme into the second method, and 

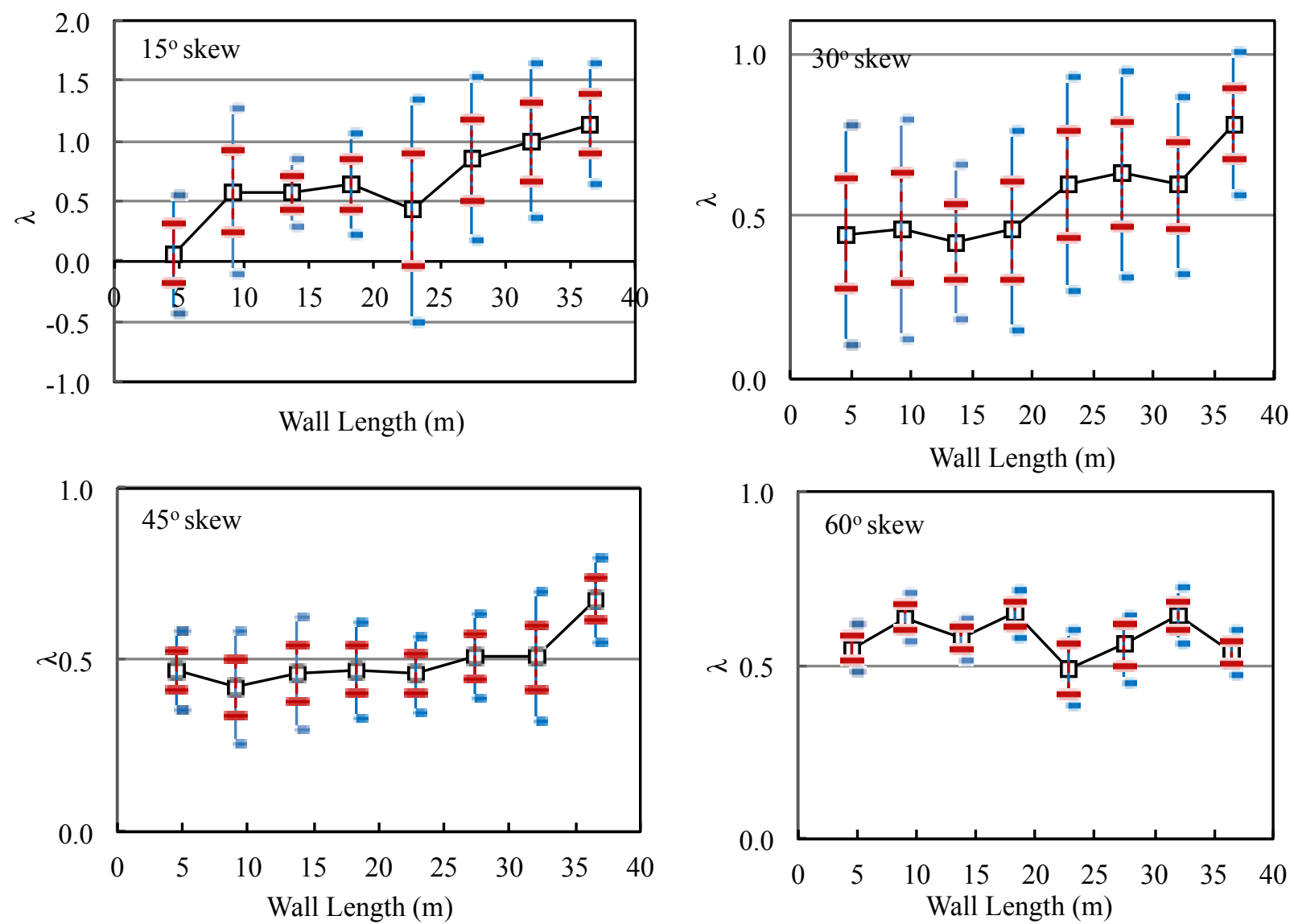

Fig. 12 The variation of $\lambda$ 's determined through least square minimization of the entire backbone curves and their $90 \%$ and $\mathbf{9 5 \%}$ sensitivity intervals (i.e., broader and narrower brackets in the figure, respectively) with skew angle and wall width.

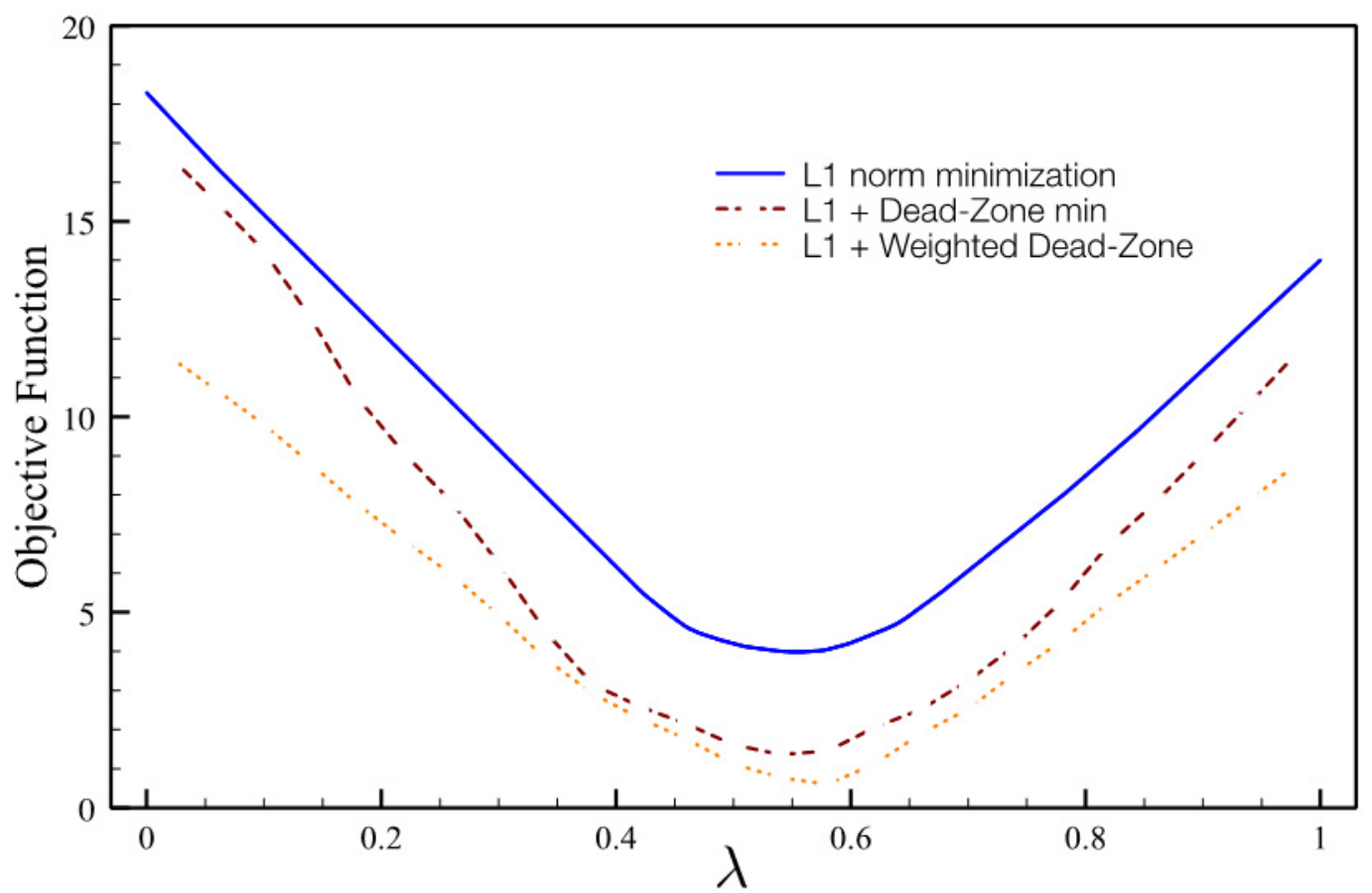

Fig. 13 Variation of $L_{1}$-norm, dead-zone $L_{1}$-norm, and weighted dead-zone $L_{1}$-norm objective functions with respect to $\lambda$. The pareto-optimal $\lambda$ values correspond to the lowest point of each curve. 
the objective function is given by:

$$
e(\lambda) \equiv \sum_{t} w_{i}\left|\lambda-\lambda_{i}\right|, w_{i} \equiv 0.1 /\left(\lambda_{i}^{90 \%-c e i l i n g}-\lambda_{i}\right)
$$

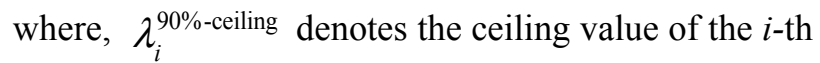
optimal $\lambda$. This type of weight $\left(w_{i}\right)$ gives more importance to narrower sensitivity brackets (while noting that the coefficient 0.1 is arbitrary and has no effect on the pareto-optimal $\lambda$ value, and it is used merely to scale the objective function in Eq. (9)).

The three approaches above yielded the pareto-optimal $\lambda$ values as $0.550,0.553$, and 0.572 , respectively. In view of many anticipated epistemic and aleatoric uncertainties associated with the present problem (e.g., uncertainties soil parameters and field compaction, finite element modeling errors, etc.), it is reasonable to round this number and use $\bar{\lambda}=0.6$ to predict the behavior of skew abutment walls using the curves estimated for straight abutments results (see, for example, Refs. [13, 15]).

It should be noted that only the capacity-based optimal $\lambda$ values (i.e., data from Fig. 11) were used in the calculations above. Also, walls with $5 \mathrm{~m}$ wall-lengths as well as $60^{\circ}$ skew angles were all included in the calculations. It goes without saying that a more accurate $\lambda$ value (than 0.6 ) for a specific case can easily be obtained by finding the closest possible $\lambda$ 's from Fig. 11 (or 12), and then by interpolating between these values.

\subsection{Blind Predictions}

In order to assess of the accuracy of the proposed $\bar{\lambda}=0.6$, some additional abutment configurations were studied. These are four new configurations that were not used as data in the optimization procedures described earlier, which include two wall lengths - -i.e., medium $(17.4 \mathrm{~m})$ and wide $(36.6 \mathrm{~m})$ - and two skew angles - moderate $\left(25^{\circ}\right)$ and severe $\left(55^{\circ}\right)$. The results are shown in Table 3. For each case, the estimated upper and lower bound walls' capacities are calculated using the proposed $\bar{\lambda}=0.6$ and Eq. (4), wherein the value $F_{\text {Straight }}^{\text {ult }}$ is computed using the LSH formulae described in Shamsabadi et al. [13]. Another set of LB and UB estimates is provided by using $\lambda$ values interpolated from data presented in Fig. 11 (the interpolated $\lambda$ 's are shown in parentheses in Table 3). Also, exact values are calculated using FEM models for each case and displayed in Table 3 in order to gauge the accuracy of the aforementioned estimates. The relative error for each calculation is computed as

$$
e_{R}=\left|F_{\lambda}^{\mathrm{ult}}-F_{\mathrm{FEM}}^{\mathrm{ult}}\right| / F_{\mathrm{FEM}}^{\mathrm{ult}}
$$

As seen, the recommended $\bar{\lambda}=0.6$ works nearly as well as the interpolated $\lambda$ values. Moreover, the results appear to be adequately accurate with a maximum relative error for predicted capacity being $12 \%$. It is important to note that the values marked

\begin{tabular}{|c|c|c|c|c|c|c|c|c|c|c|c|c|c|}
\hline & & \multicolumn{12}{|c|}{ Capacities $(\mathrm{kN})$} \\
\hline \multirow{3}{*}{ 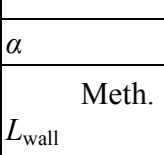 } & \multicolumn{2}{|c|}{$0^{\circ}$} & & \multicolumn{5}{|c|}{$25^{\circ}$} & \multicolumn{5}{|c|}{$55^{\circ}$} \\
\hline & \multirow{2}{*}{ LSH } & \multirow{2}{*}{ FEM } & & \multicolumn{4}{|c|}{ LSH } & \multirow{2}{*}{ FEM } & \multicolumn{4}{|c|}{ LSH } & \multirow{2}{*}{ FEM } \\
\hline & & & & With $\bar{\lambda}$ & $\mathrm{e}_{R}$ & With $\lambda_{\text {int }}$ & $\mathrm{e}_{R}$ & & With $\bar{\lambda}$ & $\mathrm{e}_{R}$ & With $\lambda_{\text {int }}$ & $\mathrm{e}_{R}$ & \\
\hline \multirow{2}{*}{$\begin{array}{l}36.6 \mathrm{~m} \\
(120 \mathrm{ft})\end{array}$} & \multirow{2}{*}{17,164} & \multirow{2}{*}{19,105} & UB & \begin{tabular}{|l}
$(0.6)$ \\
18,186
\end{tabular} & $12 \%$ & $\begin{array}{l}(0.77) \\
18498\end{array}$ & $11 \%$ & 19,359 & \begin{tabular}{|l}
$(0.6)$ \\
25,674
\end{tabular} & $3 \%$ & $\begin{array}{l}(0.57) \\
25240\end{array}$ & $1 \%$ & 24,975 \\
\hline & & & LB & $\begin{array}{l}(0.6) \\
16,482\end{array}$ & $7 \%$ & $\begin{array}{l}(0.77) \\
16768\end{array}$ & $6 \%$ & 17,797 & $\begin{array}{l}0.6) \\
14,726 \\
\end{array}$ & $8 \%$ & \begin{tabular}{|l|}
$0.57)$ \\
14477 \\
\end{tabular} & $6 \%$ & 13,595 \\
\hline \multirow{2}{*}{$\begin{array}{l}17.4 \mathrm{~m} \\
(57 \mathrm{ft})\end{array}$} & \multirow{2}{*}{8,153} & \multirow{2}{*}{8,295} & UB & $\begin{array}{l}0.6) \\
8,639\end{array}$ & $2 \%$ & $\begin{array}{l}(0.49) \\
8545\end{array}$ & $3 \%$ & 8,843 & \begin{tabular}{|l|}
$(0.6)$ \\
10,956
\end{tabular} & $7 \%$ & \begin{tabular}{|l}
$(0.65)$ \\
11,279
\end{tabular} & $4 \%$ & 11,746 \\
\hline & & & LB & \begin{tabular}{|l|}
$(0.6)$ \\
7,830
\end{tabular} & $2 \%$ & $\begin{array}{l}(0.49) \\
7744\end{array}$ & $3 \%$ & 7,979 & \begin{tabular}{|l|}
$(0.6)$ \\
6,284
\end{tabular} & $2 \%$ & $\begin{array}{l}(0.65) \\
6469\end{array}$ & $1 \%$ & 6,391 \\
\hline
\end{tabular}

Table 3 Lateral capacity predictions for the blind tests to appraise the accuracy of using $\bar{\lambda}=0.6$. 
under the LSH columns are computed purely from closed-form formulae, i.e., by using Eq. (4), $\lambda=0.6$, and the formula provided for $F_{\text {Straight }}^{\text {ult }}$ in Shamsabadi et al. [13] (or the more general version provided in Khalili-Tehrani et al. [15]), which use the backwall height and soil data as input parameters. As such, these LSH calculations are instantaneous in comparison to 3D FEM simulations. Moreover, they can be used to obtain estimates of the complete backbone curves.

\section{Conclusion}

This study provided a method to predict the lateral load-deformation behavior of seat-type skew bridge abutments under pure lateral displacements. This predictive model for skew abutments was based on two conjectures, which were put forth in the present study and tested for accuracy through numerical simulations with three-dimensional finite element models. These simulation models were identical to those that were validated against test data from a straight abutment given by Stewart et al. [8], except for the abutment skew angle, which was gradually varied in systematic parameter studies. The results from these studies suggested the use of an optimal $\lambda$ coefficient (with a recommended value of 0.6 ) with which the lateral load-displacement backbone curve of a straight abutment (as well as the lateral capacity) can be transformed into that of a skew-angled abutment given the skew angle $(\alpha)$. A previously verified and validated limit equilibrium method that uses physical parameters (such as the abutment backwall height, soil properties, etc.) supplies the lateral behavior of the corresponding straight abutment $[13,15]$.

\section{References}

[1] Mitoulis, S. 2012. "Seismic Design of Bridges with the Participation of Seat-Type Abutments." Engineering Structures 44: 222-33.

[2] NBI-National Bridge Inventory. 2002. Bridge Information System. Accessed July 1, 2014. http://www.fhwa.dot.gov/bridge/886nbi.htm.
[3] Zakeri, B., Padgett, J. E., and Amiri, G. G. 2014. "Fragility Analysis of Skewed Single-Frame Concrete Box-Girder Bridges." ASCE J. Performance of Constructed Facilities 28 (3): 571-82.

[4] Caltrans, S. D. C. 2010. Caltrans Seismic Design Criteria Version 1.6. California Department of Transportation, Division of Engineering Services, Office of Structure Design, Sacramento, CA.

[5] Kaviani, P., Zareian, F., and Taciroglu, E. 2014. Performance-Based Seismic Assessment of Skewed Bridges. PEER Report No. 2014/1, Pacific Earthquake Engineering Research Center, Berkeley, CA.

[6] Rollins, K., and Jessee, S. 2013. "Passive Force-Deflection Curves for Skewed Abutments." $J$. Bridge Eng. 18 (10): 1086-94.

[7] Shamsabadi, A., Rollins, K. M., and Kapuskar, M. 2007. "Nonlinear Soil-Abutment-Bridge Structure Interaction for Seismic Performance-Based Design." ASCE J. Geotech. \& Geoenv. Eng. 133 (6): 707-20.

[8] Stewart, J. P., Taciroglu, E., Wallace, J. W., Ahlberg, E. R., Lemnitzer, A., Rha, C. S., Khalili-Tehrani, P., Keowen, S., Nigbor, R. L., and Salamanca, A. 2007. Full Scale Cyclic Testing of Foundation Support Systems for Highway Bridges. Part II: Abutment Backwalls. Report No. UCLA-SGEL 2007/02, Structural and Geotechnical Engineering Laboratory, University of California, Los Angeles.

[9] Vermeer, P. A., and Brinkgreve, R. B. J. 1998. Plaxis: Finite-Element Code for Soil and Rock Analyses (Version 7.1). Rotterdam, The Netherlands: Balkema.

[10] Brinkgreve, R. B., and Broere, W. 2008. Plaxis 3D Foundation Manual v.2.2. The Netherland: Delft University of Technology and Plaxis.

[11] Duncan, J. M., and Chang, C. Y. 1970. "Nonlinear Analysis of Stress and Strain in Soils." Journal of the Soil Mechanics and Foundations Division 96 (5): 1629-53.

[12] Schanz, T., Vermeer, P. A., and Bonnier, P. G. 1999. "The Hardening Soil Model: Formulation and Verification." In Proc. Plaxis Symp.: Beyond 2000 in Computational Geotechnics, edited by Brinkgreve, R. B. J. Balkema, Rotterdam: The Netherlands, 281-96.

[13] Shamsabadi, A., Khalili-Tehrani, P., Stewart, J. P., and Taciroglu, E. 2010. "Validated Simulation Models for Lateral Response of Bridge Abutments with Typical Backfills." ASCE J. of Bridge Eng. 15 (3): 302-11.

[14] ASTM Standard D155. 2009.Standard Test Methods for Laboratory Compaction Characteristics of Soil Using Modified Effort. ASTM International, West Conshohocken, PA.

[15] Khalili-Tehrani, P., Taciroglu, E., and Shamsabadi, A. 2010. "Backbone Curves for Passive Lateral Response of 
Walls with Homogeneous Backfills." Soil-Foundation-Structure Interaction, edited by Orense,
R. P., Chouw, N., and Pender, M. J. Vol. 2. New Zealand: University of Auckland, 149-54. 